Research Article

\title{
Research on Microscopic Evolution Laws of Sandstone Deformation and Failure Based on the Particle Discrete Element Method
}

\author{
Zhiwei Cai, ${ }^{1}$ Tongqing $\mathrm{Wu} \mathbb{D}^{2,3,4} \mathrm{Jian}^{\mathrm{Lu}}{ }^{2}$ Yue $\mathrm{Wu},{ }^{2,3,4}$ and Nianchun $\mathrm{Xu}^{2,3,4}$ \\ ${ }^{1}$ CCTEG Chongqing Engineering (Group) Co., Ltd., Chongqing 400016, China \\ ${ }^{2}$ School of Civil Engineering and Architecture, Chongqing University of Science and Technology, Chongqing 401331, China \\ ${ }^{3}$ Key Laboratory of Geological Hazards Mitigation for Mountainous Highway and Waterway, \\ Chongqing Municipal Education Commission, Chongqing Jiaotong University, Chongqing 400074, China \\ ${ }^{4}$ Chongqing Key Laboratory of Energy Engineering Mechanics \& Disaster Prevention and Mitigation, Chongqing 401331, China
}

Correspondence should be addressed to Tongqing Wu; 2008058@cqust.edu.cn

Received 7 April 2021; Accepted 16 August 2021; Published 26 August 2021

Academic Editor: Gan Feng

Copyright (c) 2021 Zhiwei Cai et al. This is an open access article distributed under the Creative Commons Attribution License, which permits unrestricted use, distribution, and reproduction in any medium, provided the original work is properly cited.

\begin{abstract}
The fracture of sandstone is closely related to the condition of internal microcracks and the fabric of micrograin. The macroscopic mechanical property depends on its microscopic structures. However, it is difficult to obtain the law of the microcrack growth under loading by experiments. A series of microscopic sandstone models were established with particle flow code 3D (PFC3D) and based on the triaxial experiment results on sandstones. The experimental and numerical simulations of natural and saturated sandstones under different confining pressures were implemented. We analyzed the evolution of rock deformation and the rock fracture development from a microscopic view. Results show that although the sandstones are under different confining pressures, the law of microcrack growth is the same. That is, the number of the microcracks increases slowly in the initial stage and then increases exponentially. The number of shear cracks is more than the tensile cracks, and the proportion of the shear cracks increases with the increase of confining pressure. The cracking strength of natural and saturated sandstones is $26 \%$ and $27 \%$ of the peak strength, respectively. Under low confining pressure, the total number of cracks in the saturated sample is $20 \%$ more than that of the natural sample and the strongly scattered chain is barely seen. With the increase of the confining pressure, the effect of water on the total number of cracks is reduced and the distribution of the strong chain is even more uniform. In other words, it is the confining pressure that mainly affects the distribution of the force chain, irrespective of the state of the rock, natural or saturated. The research results reveal that the control mechanism of shear crack friction under the different stress states of a rock slope in the reservoir area provides a basis for evaluating the stability of rock mass and predicting the occurrence of geological disasters.
\end{abstract}

\section{Introduction}

Rock is anisotropic aggregates bonded by multiple mineral particles with different microscopic structures such as internal particles, pores, and types of cement, often found in mining [1,2] and tunneling [3]. On account of long-term geologic tectonism and the diversity of occurrence environment, rocks generally contain many randomly distributed defects, including fractures, joints, and beddings. They are featured by apparent heterogeneity, discontinuity, and anisotropy under loading, with significant uniqueness in mechanical properties and deformation failure laws. The strength of rock drops when touching water, accompanied by a water softening effect. Many geotechnical, hydraulic projects have been constructed in recent years, which triggered significant problems, including instability and safety accidents due to subsurface action, thereby causing great human and property losses. Consequently, investigating the deformation-induced failure rules and mechanism of natural and saturated rocks from macroscopic and 
microscopic aspects has crucial practical significance and great engineering application values in accurately predicting the stability of rock engineering and effectively ensuring safety.

Currently, scholars have conducted a great deal of research on rock's fracture and deformation rules and mechanisms $[4,5]$. Hoek et al. have achieved many fruitful achievements regarding rock's deformation and fracturing rules [6]. Hazzard et al. analyzed the formation and development of cracks in the brittle rocks with dynamic and microscopic mechanical models and performed laboratory tests for comparison [7]. Martin determined the characteristic strengths (including the crack initiation strength, the crack damage stress strength, and the peak strength) according to the stress threshold corresponding to the inflection point of strain on the stress-strain curve $[8,10]$. Zhang et al. analyzed the condition of flaky rocks with the stress threshold value in rock's progressive failure and made a comparison with the other types of rocks [11]. Xie et al. focused on energy accumulation and release rules of rock units during the deformation failure process based on elastic theory [12]. Finally, Deng et al. carried out comprehensive research on red bed mechanical properties and deformation failure characteristics [13].

Researchers also conducted in-depth studies on the development mechanisms of rock cracks in previous studies but cannot directly measure the overall development and evolution process of cracks in the rock samples under loading. It is pretty challenging to gain a comprehensive understanding of rock's deformation and failure mechanism. With the rapid development and extensive applications of numerical simulation techniques $[14,15]$, both crack development rules and failure mode of rock under loading can be analyzed by simulating the macromechanical parameters of rock using numerical calculation software on micro level. At present, a commercial software, particle flow code (PFC), developed by Itasca Co. Ltd., has witnessed extensive applications [16]. PFC, which was first proposed by Cundall and Strack for simulating the motion of rigid balls and the related interaction based on the ideal of discrete elements and particle discrete element method, can overcome the macrocontinuity hypothesis in continuum mechanics and employ micromechanical parameters for simulating the rock's macromechanical response [17]. PFC mainly includes two bonding models-parallel bond (PB) model and contact bond (CB) model $[18,19]$. The boning among mineral particles in the rock can be simulated by specifying the bonding type among particles. Accordingly, the formation and development of microcracks in the rock can be simulated with bonding failure among particles to reveal microcrack development rules in the rock. Potyondy et al. employed the bonded-particle model in PFC for analyzing the fracture mechanism of rock [19]. Hazzard et al. used the bonded-particle model construct the rock sample and simulated the coalescence and development process of cracks in the rock under compressive stress by the fracture of the bonding linkage among particles [7]. Cho et al. established the granite model with clump units for performing Brazilian Split test, uniaxial compression, and triaxial compression tests and analyzed the effects of microparameters on macromechanical property in detail [18]. Backstrom et al. conducted a uniaxial compression failure model on dry and water-bearing granite samples via discrete element method (DEM) [20]. Fakhimi et al. focused on the failure model of sandstone under biaxial compression test via PFC2D analysis [21]. Jiang et al. employed PFC2D for fully simulating the uniaxial compression test of rock under water softening-chemical weathering effect and analyzed the change of the rock's mechanical properties and failure mode on both macrolevels and microlevels [22]. Based on the discrete element software PFC2D, Liu et al. explored the microstructure of argillaceous sandstone after dray-wet cycles and concluded the particle's contact network effects, force chain distribution, and crack distribution pattern [23]. Cong et al. determined the microscopic parameters of rocktype materials in combination with laboratory loading/ unloading tests of marbles and explored the quantitative correlation among macro/microparameters based on particle flow principle [24]. Tian et al. selected the cluster unit in PFC2D and conducted a simulation on two unloading confining pressure paths of sandstone for contrastive analysis [25]. Using the discrete element method, Yuan et al. investigated the macro/micromechanical responses of internal particle components in the rock under compressive loading [26].

The shoreside rock would frequently suffer from water saturation and high pressure in a wet period. Otherwise, the shoreside rock would be exposed to a relatively dry environment. Therefore, it is significant and necessary to lucubrate mechanical properties damage characteristics of the rock in this condition. This study focused on sandstone on the bank slope of a reservoir in Chongqing, China, and established the microstructural model of the sandstone with PFC3D software based on three-dimensional (3D) particle flow theory. In combination with laboratory test results, the micromechanical parameters of sandstone were determined, and the micromechanical numerical model of sandstone was constructed for numerical simulating the deformation and failure evolution process of natural and saturated sandstones under different stress levels. The simulation results based on the micro perspective comprehensively reveal the deformation and failure evolution rules and mechanisms of natural and saturated sandstones under different combining pressures, which provides a basis for the evaluation of the stability of rock mass and the prediction of the occurrence of geological disasters under the wet-natural condition.

\section{Sample Preparation and Experimental Equipment}

2.1. Sample Preparation. A typical bank slope comprised of rock from the Three Gorges reservoir area was selected, and samples came from the hydrofluctuation belt. Sandstone cores from in situ rock mass were remachined in the Chongqing Key Laboratory of Energy Engineering $\mathrm{Me}$ chanics and Disaster Prevention and Mitigation. Besides, samples with obvious defects were rejected, according to the International Society of Rock Mechanics Test Procedures 
(ISRM) (Fairhurst and Hudson 1993). All tested samples were cylindrical with a length of $100 \mathrm{~mm}$ and a diameter of $50 \mathrm{~mm}$, and diameter error shall be no more than $0.3 \mathrm{~mm}$ and the error of end face nonparallelism no more than $0.05 \mathrm{~mm}$. In addition, P-wave velocity and rebound value were scrutinized to eliminate samples with extreme outliers. Sketches of machined sandstone samples are shown in Figure 1.

X-ray diffraction and an electronic microscope were employed to identify the mineral contents of the specimens. Figure 2 illustrates the microscopic structure of sandstone. The identification test showed that the rock class was medium-fine detritus feldspathic quartz sandstone, and the mineral contents (mass fraction) were as follows: quartz $55 \%$, feldspar $25 \%$, hornblende $9 \%$, olivine $3 \%$, biotite $3 \%$, and interstitial matter 5\%. The sandstone was hard and compact, with void cementation.

2.2. Experimental Equipment. The tests were conducted mainly by using the TFD-2000 computer servo controlled triaxial rock rheology testing machine. The maximum axial test force is $2000 \mathrm{kN}$, and the maximum confining pressure is $100 \mathrm{MPa}$. Temperature ranges from room temperature to $200^{\circ} \mathrm{C}$. The testing machine is capable of performing mechanical tests under multifield coupling conditions, including uniaxial and triaxial compression tests, uniaxial and triaxial rheological tests, high-temperature triaxial test, hightemperature triaxial rheological tests, and room-temperature and high-temperature seepage tests on the rock. The test equipment is shown in Figure 3.

The triaxial compression tests were conducted using the TFD-2000 rock rheology test machine, as shown in Figure 3(a). The sample is sealed with a shrinkable heat tube, and the axial and lateral strains are collected by displacement sensors, as shown in Figure 3(b). We set the testing temperature to $20 \pm 2^{\circ} \mathrm{C}$.

\section{Numerical Model and Microscopic Parameters}

3.1. Numerical Model for the Sandstone Sample. The PFC3D model for conventional compression test consists of two-part wall and particles. To be specific, the particles are wrapped by the wall. The infinitely extended plane loading plates are on both top and bottom, while the sidewall is nearly the outer wall of the cylinder composed of innumerable tiny rectangular planes. When the model works, the axial load is applied to the sample by setting the upper and the lower loading plates (mt_psr). According to the actual side of the sample and the computer performance, the minimum particle radius and the particle diameter can be set as $R_{\min }=1.5 \mathrm{~mm}$ and $R_{\max } l$ $R_{\min }=1.5$. The particle diameter follows the Gaussian distribution in the whole model. Figure 4 shows the PFC geometrical model of the sandstone sample.

To lower the effect on the model sample during loading, the loading speed of the loading plate rises in ladder pattern and gradually achieves the target value. The stress/strain value of the sample can be recorded by compiling the functions with the fish language in the program.

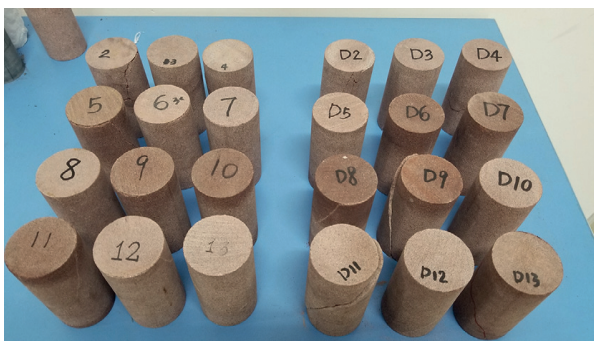

FIGURE 1: Sandstone specimens.

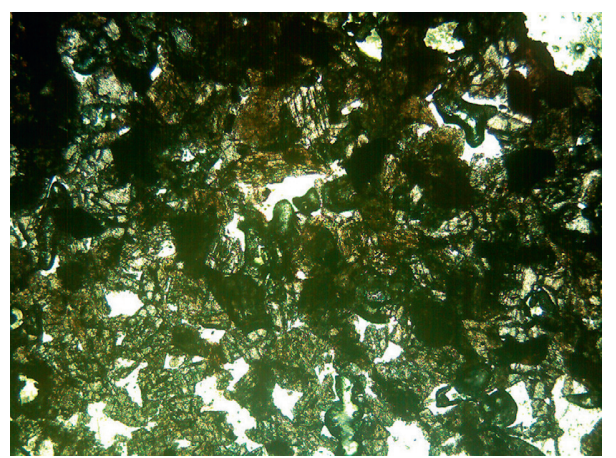

Figure 2: The microscopic structure of sandstone.

3.2. Microscopic Parameters of the Sandstone Numerical Model. The microscopic parameters of the rock were obtained by comparing stress-strain curves and key parameters (mainly including peak strength, peak strain, elastic modulus, and Poisson's ratio) after repeated trials and checks. Different contact types should specify different types of materials. Rock materials generally adopt a parallel bonding model and linear stiffness model. The microscopic parameters differ under different confining pressures. The rock peak strengths during uniaxial and triaxial compression tests in PFC simulation were subjected to normal and tangential bonding strengths. The declining pattern of the prepeak curve changes with the friction coefficient. The rock becomes ductile at high confining pressure. Therefore, different friction coefficients should be appropriately set following other confining pressures. Meanwhile, the friction coefficient can also affect the peak strength to a certain degree. After calibrating micromechanical parameters, this study carried out some macromechanical experiments for calibrating and determining some basic microparameters, as listed in Table 1.

\section{Contrastive Analysis between Laboratory Test Results and PFC Numerical Simulation Results of Sandstones}

Both uniaxial and triaxial compression tests were conducted on natural and saturated sandstone samples. It must be noted that the confining pressure was set as 5, 10, and $15 \mathrm{MPa}$ in the triaxial compression test. Moreover, using the same samples, loading mode, and micromechanical parameters, micromechanical numerical simulation was 


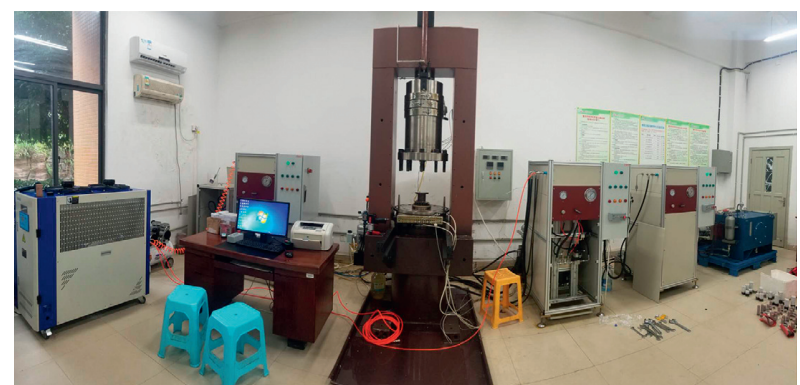

(a)

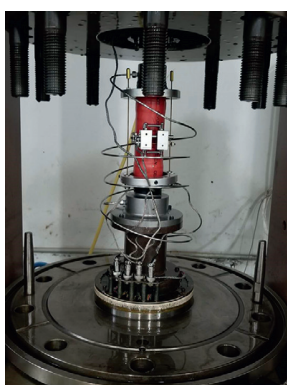

(b)

Figure 3: TFD-2000 computer servo controlled triaxial rock rheology testing machine. (a) Appearance of the test apparatus. (b) Pressure chambers.

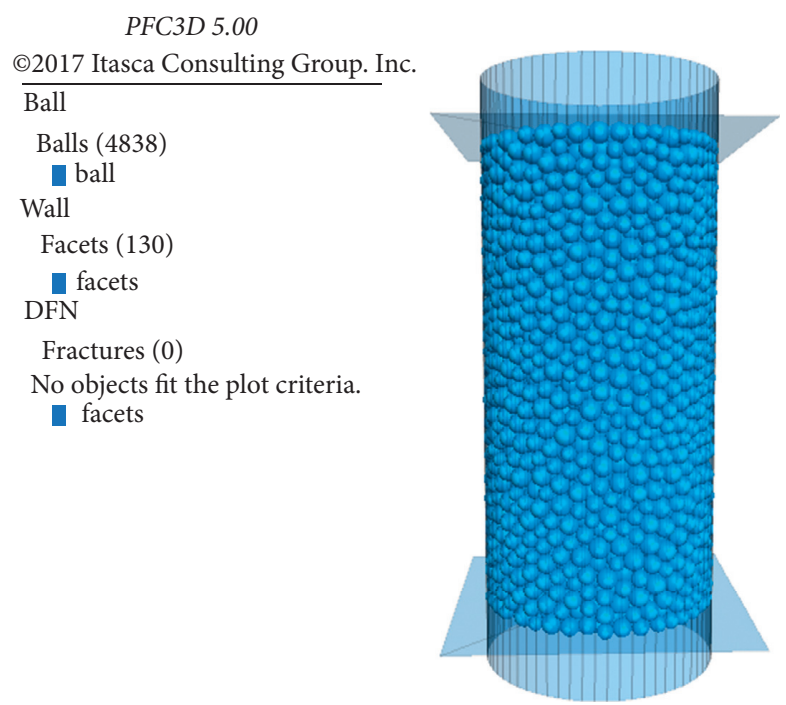

Figure 4: A numerical model for the sandstone sample.

TABle 1: Microscopic parameters of the sandstone numerical model.

\begin{tabular}{lc}
\hline Microscopic parameters & Values \\
\hline Ball density $\rho\left(\mathrm{kg} / \mathrm{cm}^{3}\right)$ & 2430 \\
Minimum ball radius $R_{\min }(\mathrm{mm})$ & 1.5 \\
Ball size ratio $R_{\max } / R_{\min }$ & 1.5 \\
Ball-ball contact modulus $E_{c}(\mathrm{GPa})$ & $18 \pm 10$ \\
Particle stiffness ratio $k_{n} / k_{s}$ & 2.5 \\
Parallel-bond modulus $E_{c}(\mathrm{GPa})$ & $18 \pm 10$ \\
Parallel-bond normal strength $\sigma_{n}(\mathrm{MPa})$ & $57 \pm 20$ \\
Particle friction coefficient $\mu$ & 0.5 \\
\hline
\end{tabular}

conducted on natural and saturated sandstone samples, during which the confining pressure was set as $5,10,15,20$, 30,40 , and $50 \mathrm{MPa}$, respectively. The numerical simulation results were compared with laboratory test data. In the meantime, both macro- and micromechanical properties of natural and saturated sandstone samples at confining pressures of $20,30,40$, and $50 \mathrm{MPa}$ were predicted. The comparison between laboratory test and numerical simulation results is shown in Table 2 and Figures 5 and 6 .

As shown in Table 2 and Figures 5 and 6, the stress/strain curves in numerical simulation fit well with the laboratory test results under both uniaxial stress and triaxial stress at different confining pressures. The deviations of peak compressive strength and elastic modulus are controlled within $10 \%$, and the departure of the peak strain is controlled within $6 \%$. Figure 7 shows the variations of the peak compressive strength with confining pressure under two conditions.

According to the Mohr-Coulomb strength criterion, the cohesive force and the internal friction angle in laboratory test and PFC numerical simulation can be obtained, as listed in Table 3. However, the cohesive force in the numerical simulation was more significant through comparison, while the internal friction angle was lower than the test values. This can be attributed to the difference between the generated particle model and the microstructures of actual samples, as Cho and Potyondy have pointed out $[18,19]$.

\section{Micromechanical Response Characteristics of Sandstones under Different Stresses}

5.1. Deformation and Fracture Evolution Rules of Sandstones. Next, we investigated the micromechanical response characteristics of sandstone under different stresses with the micronumerical model of sandstone in PFC3D. By taking 
TABLE 2: Comparison between the laboratory test and PFC3D numerical simulation results for sandstones.

\begin{tabular}{|c|c|c|c|c|c|c|c|}
\hline \multirow{2}{*}{$\begin{array}{l}\text { Confining } \\
\text { pressure } \\
(\mathrm{MPa}) \\
\end{array}$} & \multirow{2}{*}{$\begin{array}{l}\text { Sample } \\
\text { state }\end{array}$} & \multicolumn{2}{|c|}{ Peak strength } & \multicolumn{2}{|c|}{ Elastic modulus } & \multicolumn{2}{|c|}{ Peak strain } \\
\hline & & $\begin{array}{l}\text { Experimental } \\
\text { value }(\mathrm{MPa})\end{array}$ & $\begin{array}{l}\text { PFC modelling } \\
\text { value }(\mathrm{MPa})\end{array}$ & $\begin{array}{l}\text { Experimental } \\
\text { value }(\mathrm{MPa})\end{array}$ & $\begin{array}{l}\text { PFC modelling } \\
\text { value }(\mathrm{MPa})\end{array}$ & $\begin{array}{l}\text { Experimental } \\
\text { value }(\mathrm{MPa})\end{array}$ & $\begin{array}{l}\text { PFC modelling } \\
\text { value }(\mathrm{MPa})\end{array}$ \\
\hline \multirow{2}{*}{0} & Natural & 68.17 & 66.87 & 12.74 & 16.11 & 4.67 & 4.67 \\
\hline & Saturated & 37.13 & 31.80 & 10.22 & 8.31 & 4.20 & 4.16 \\
\hline \multirow{2}{*}{5} & Natural & 78.41 & 78.21 & 14.31 & 15.62 & 5.96 & 5.95 \\
\hline & Saturated & 71.64 & 71.20 & 11.66 & 13.84 & 6.37 & 6.46 \\
\hline \multirow{2}{*}{10} & Natural & 102.60 & 107.40 & 20.91 & 20.59 & 6.21 & 6.00 \\
\hline & Saturated & 77.02 & 76.29 & 15.21 & 18.07 & 7.34 & 7.78 \\
\hline \multirow{2}{*}{15} & Natural & 115.29 & 116.61 & 29.05 & 25.26 & 6.94 & 6.75 \\
\hline & Saturated & 97.93 & 99.01 & 21.36 & 21.33 & 7.27 & 7.19 \\
\hline
\end{tabular}

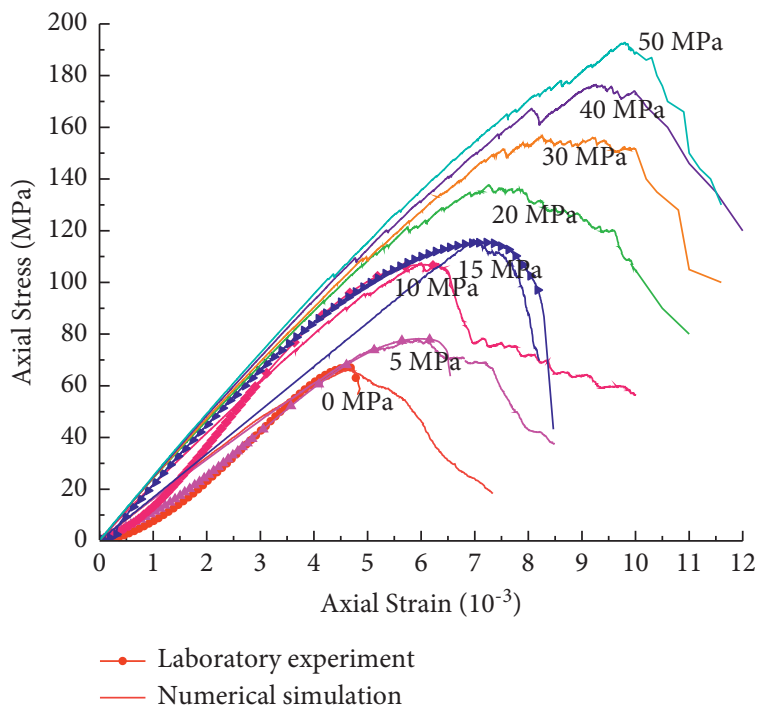

FIGURE 5: Sandstone stress-strain curves under different confining pressures (natural).

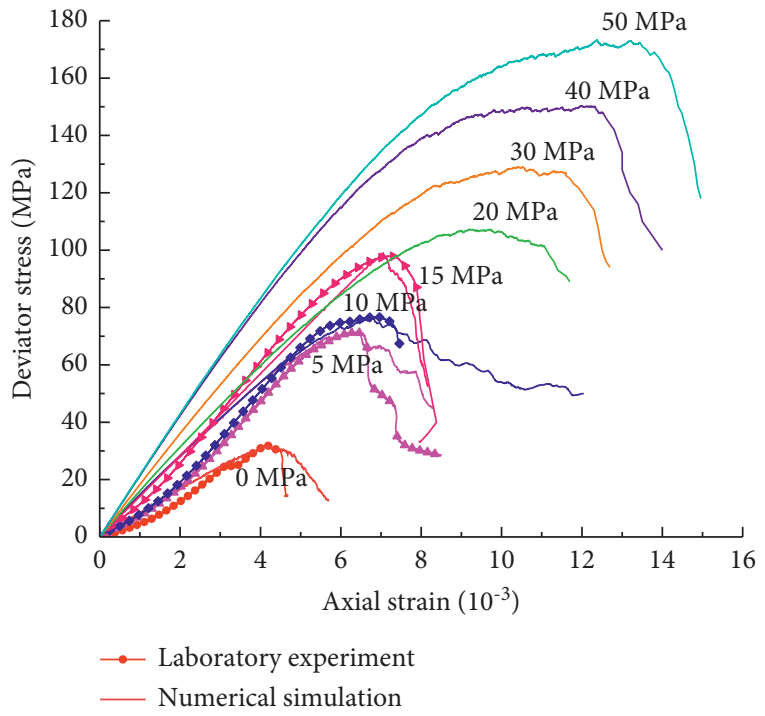

FIgURE 6: Sandstone stress-strain curves under different confining pressures (saturated). the natural sandstone at a confining pressure of $5 \mathrm{MPa}$ as an example, the micromechanical evolution rules of the sandstone sample under the loading path were concluded, as shown in Figures 8 and 9. The data such as the number of fractures, the fracturing mode, and the fracture position were captured using the program compiled with fish language in PFC software. 9:

The following conclusions are drawn from Figures 8 and

(1) At the beginning of loading, the stress/strain curve shows an unmistakable concave shape. During the loading process, many microfractures were closed under the external force, while the pores between rock molecules were gradually compacted. Therefore, the strain rate first increased and then dropped with the stress. Thus, the sample underwent the transition from compaction to linear elastic deformation. In the compaction phase, since the microfractures have not been fully closed and the faults were inhibited, the radial strain of the sample changed slightly. However, no new fractures were formed in the sample.

(2) In the linear elastic deformation phase, fractures began to appear in the sample and then developed slowly and extended stably. In particular, the tensile fractures occurred earlier and grew more rapidly than the shear fractures. The number of microfractures in the sample increased slowly while the microfractures were not interconnected.

(3) As the stress reached $80 \% \sim 90 \%$ of the peak strength of the sandstone, the microfractures began to develop rapidly and were gradually connected. As a result, the number of tensile fractures was more significant than that of shear fractures.

(4) As the stress reached the peak strength, the sample was destroyed, and more microfractures were formed. After the stress became near the peak strength, the number of microstructures in the sample increased rapidly in an exponential pattern. Moreover, the growth rate of the tensile fractures was significantly more extensive than that of the shear fractures. At that time, the sample was fully destroyed. As a result, obvious tensile and shear 


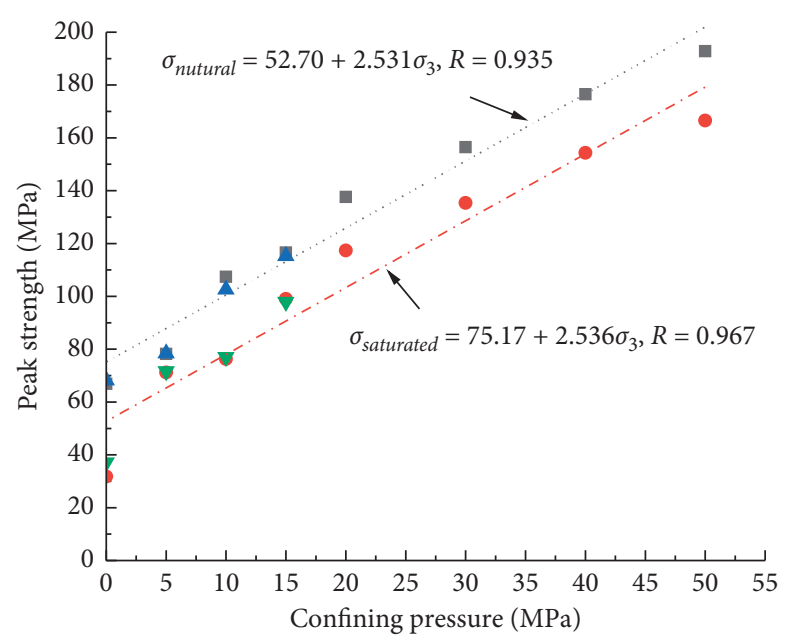

$\begin{array}{lc}\text { - Numericalsimulation } & \boldsymbol{\Delta} \begin{array}{l}\text { Laboratory experiment } \\ \text { (natural) }\end{array} \\ \text { - Numerical simulation } & \boldsymbol{\nabla} \text { Laboratoryexperiment } \\ \text { (saturated) } & \text { (saturated) }\end{array}$

FiguRE 7: Relation curve of peak strength and confining pressure.

TABLE 3: Intensity parameter of sandstone.

\begin{tabular}{lccr}
\hline Category & Sample state & $c(\mathrm{MPa})$ & $\varphi\left(^{\circ}\right)$ \\
\hline \multirow{2}{*}{ Laboratory experiment } & Natural & 15.7 & 35.58 \\
& Saturated & 13.9 & 31.18 \\
\hline \multirow{2}{*}{ Numerical simulation } & Natural & 14.7 & 37.52 \\
& Saturated & 13.5 & 31.94 \\
\hline
\end{tabular}

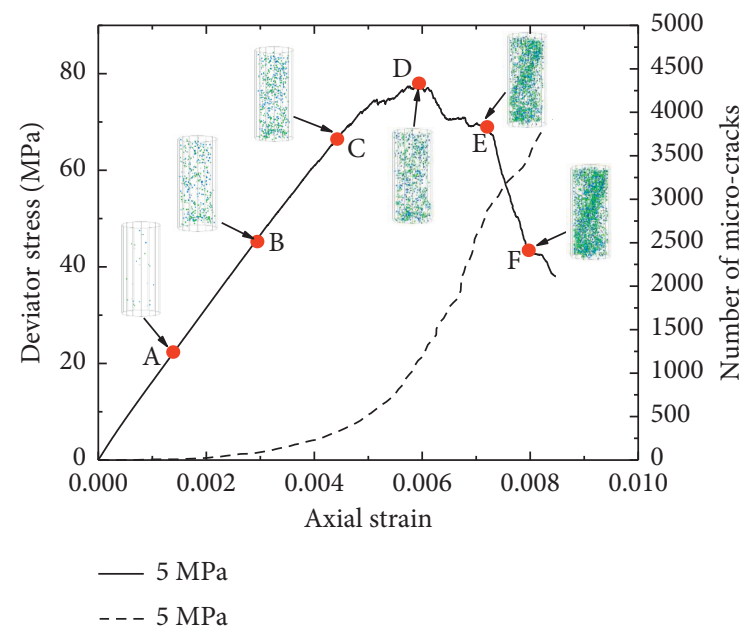

(a)
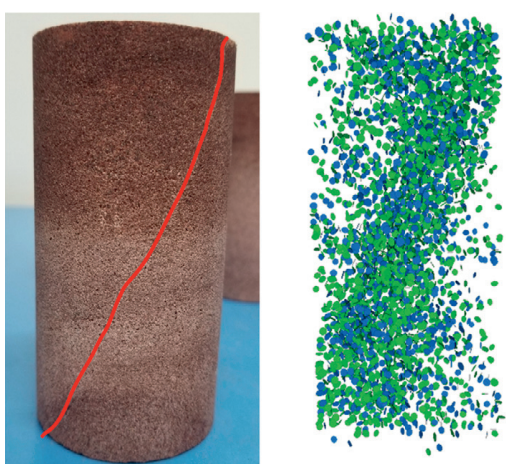

(b)

FIgURE 8: The evolution process of deformation and microcrack under the loading path (confining pressure is $5 \mathrm{MPa}$ ). (a) PFC3D numerical simulation results for natural sandstone (confining pressure is $5 \mathrm{MPa}$ ). (b) Failure patterns of specimens of sandstone and PFC3D numerical simulation.

fractures, visible to the human eye at the macro level, appeared in the sample. In addition, a significant number of microfractures were distributed in the sample on the micro level. Conclusively, the deformation and fracture process of the sandstone sample mainly consists of the compaction of microfractures, the formation and development of tensile and shear fractures, the interconnection of microfractures, the unstable development of microfractures, and the macrodamage. The particle failure diagram via PFC simulation was consistent with the actual macrofailure mode in the laboratory test. 


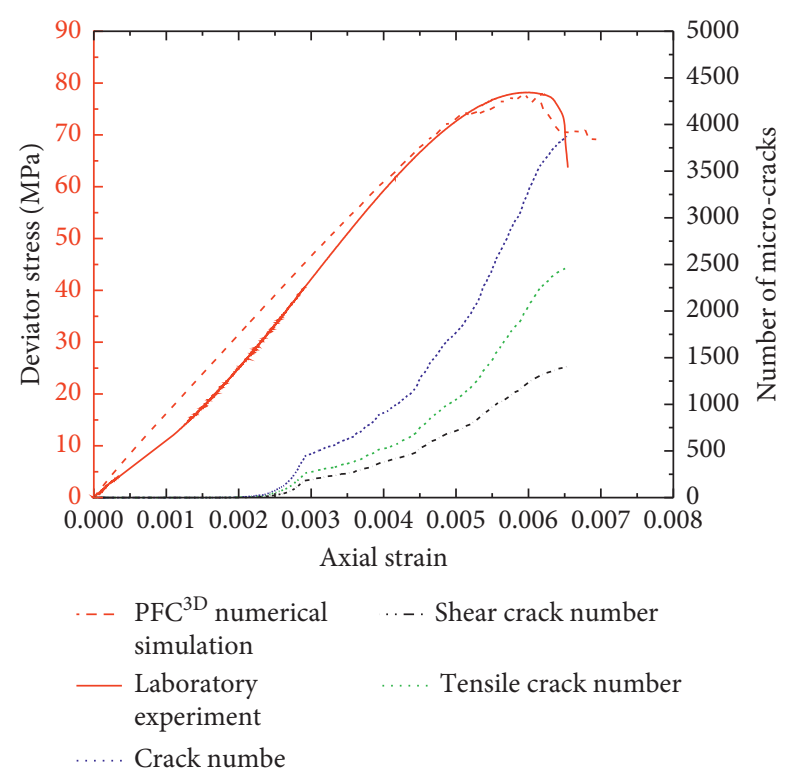

FIGURE 9: Stress-strain curve of sandstone samples and the evolution of microcracks (confining pressure is $5 \mathrm{MPa}$ ).

\subsection{Failure Mechanism of the Sandstone under Different} Stresses. According to the development degree and the evolutional level of microfractures, the stress/strain curve of the sandstone sample under uniaxial or low confining pressure can be roughly divided into three phases, as shown in Figure 10.

Three phases, denoted as Phase A, Phase B, and Phase C, can be observed in Figure 10. In Phase A, only a tiny number of microfractures (in single digit) appeared in the sample, and the original fractures in the rock were closed under compaction, suggesting the linear elastic deformation phase. In Phase $B$, as the stress increased gradually, the sandstone also underwent linear elastic deformation. The tensile fractures appeared earlier and developed more rapidly than the shear fractures. Some parallel bonds cracked. The starting point of the axial stress corresponding to the beginning of the appearance of original or new fractures, generally defined as the fracture initiation strength, is generally $30 \% \sim 50 \%$ of peak strength. In Phase C, the tensile fractures increased rapidly in number and became gradually interconnected in the sample, accompanied by the decline in parallel bonding strength. Macrofractures began to appear in the sample, and sliding friction was generated. The parallel bonding tangential strength dropped rapidly. The stress also decreased drastically as reaching the peak strength, which was indicative of macrofracture of the sandstone. Huang et al. pointed out that the rock was initially damaged when the number of the microfractures was $0.1 \%$ of the value at the peak strength so that the rock's fracture initiation strength can be determined [27]. Accordingly, the numerical simulation data were organized, and natural and saturated sandstone values under different confining pressures were derived, as shown in Figure 11.

It can be seen from Figure 11 that the fracture initiation strengths of natural and saturated sandstone samples were

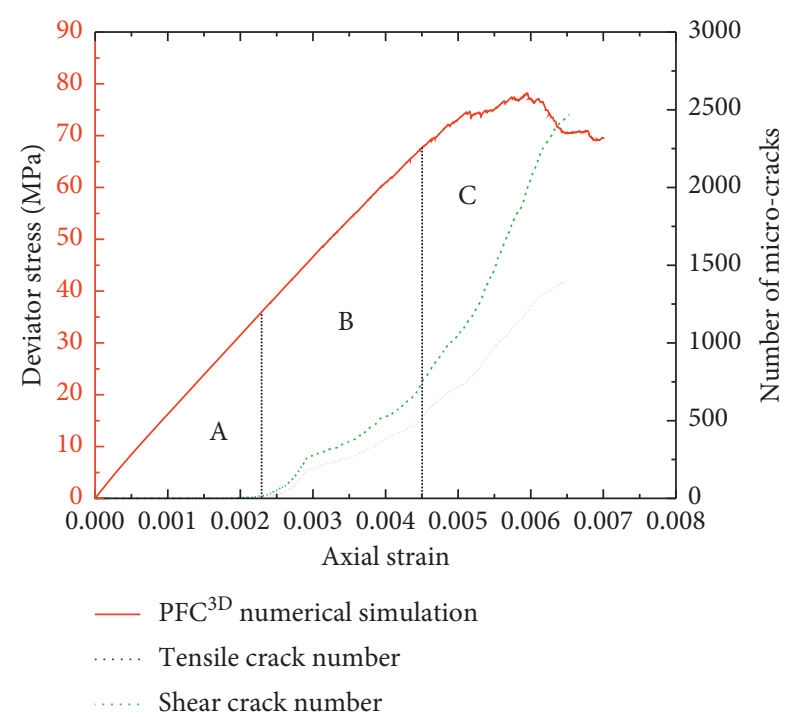

FIGURE 10: Evolution of microcrack incubation for the sandstone sample.

$26 \%$ and $27 \%$ of peak strengths. The fracture initiation strength varied greatly at low confining pressure. At over $20 \mathrm{MPa}$, the fracture initiation strengths of natural and saturated sandstone samples were $34 \%$ and $24 \%$ of peak strengths. Since the fracture initiation lasted for a long time, the fracture initiation strengths were $10 \% \sim 40 \%$ of peak strengths. Only a few microfractures appeared. Therefore, it is a feature to describe the fracture initiation strength of the sandstone by the mean value of the percentage of different confining pressures.

Figures 12 and 13 display the stress-strain curves and fracture evolution rules of natural and saturated sandstone samples under different confining pressures via PFC numerical simulation.

Figures 12 and 13 show that more microfractures appeared at a higher confining pressure under the same condition. The evolutions of microfractures under different confining pressures exhibit an S-shaped growth pattern. At low confining pressure, the deviatoric stress reached the stress threshold of the fracture initiation strength, and the sample began to fracture. At that time, only a very few microfractures appeared and grew slowly. On the micro level, only a few or dozens of particles were destroyed. As the deviatoric stress reached $70 \% \sim 80 \%$ of peak strength, the number of microfractures increased rapidly. Next, as the deviatoric stress reached the peak strength, the number of microfractures significantly increased in an exponential pattern, and the numerical model was destroyed. As a moderate confining pressure, the microcracks in the sandstone sample increased rapidly in number, and peak strength rose, suggesting that the sample can sustain a more significant pressure. Meanwhile, the number of microfractures increased, but the sample would not be destroyed immediately but still showed certain ductility. At higher confining pressure, the microfractures grew at consistent rates, and no obvious inflection point appeared in the evolutional curve of the microfractures. 


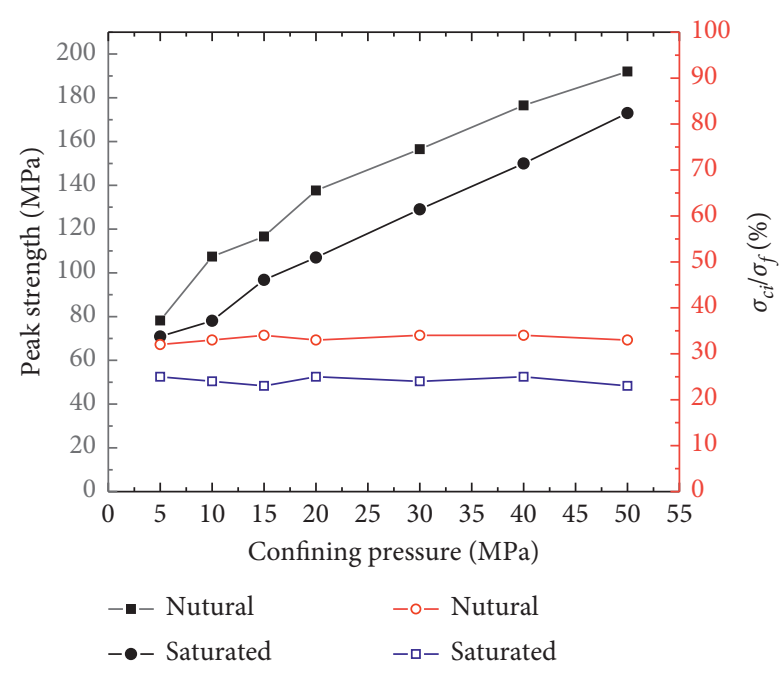

FIGURE 11: Sandstone's diagram of initial fracture strength.

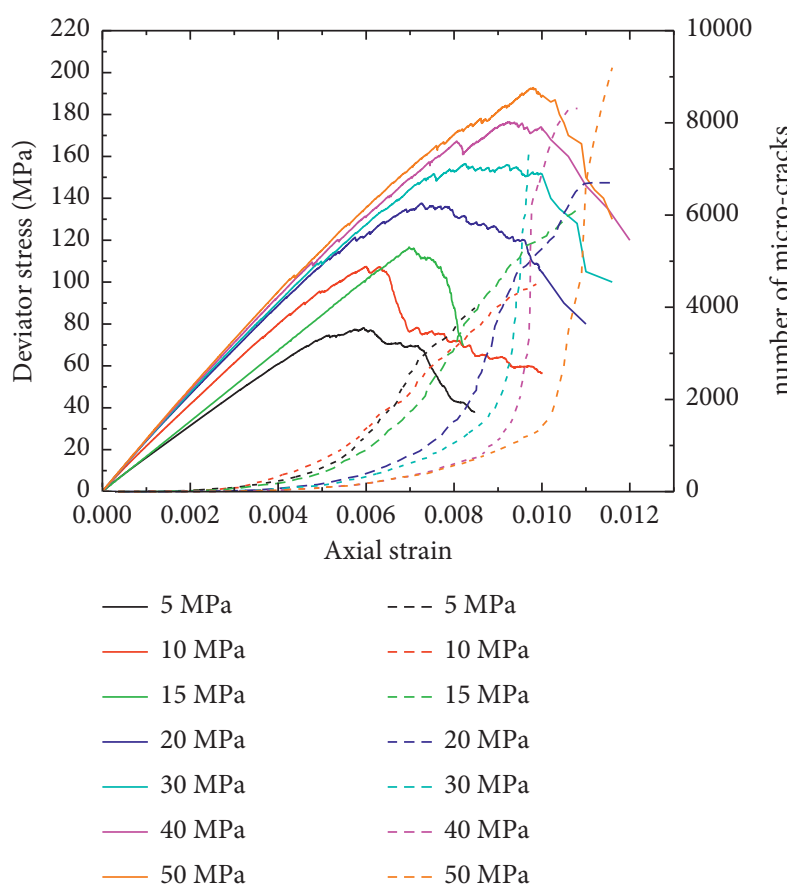

FIGURE 12: Deviator stress and microcracks number versus axial strain under different confining pressures (natural).

5.3. Fracturing of the Sandstone Samples under Different Moisture Conditions. Figure 14 displays the development of microfractures with the confining pressure. Based on the total number of fractures in the natural and the saturated samples at different confining pressures, the saturated sample showed more substantial ductility because of water, longer loading process, and higher peak strain. Moreover, the number of fractures in the saturated sample exceeded that in the natural sample. At low confining pressure, the total number of fractures in the saturated sample was $20 \%$ greater than that in the natural sample. The number of fractures in the samples increased almost consistently with the confining pressure by only $1 \% \sim 5 \%$. It is noted that the number of fractures in the

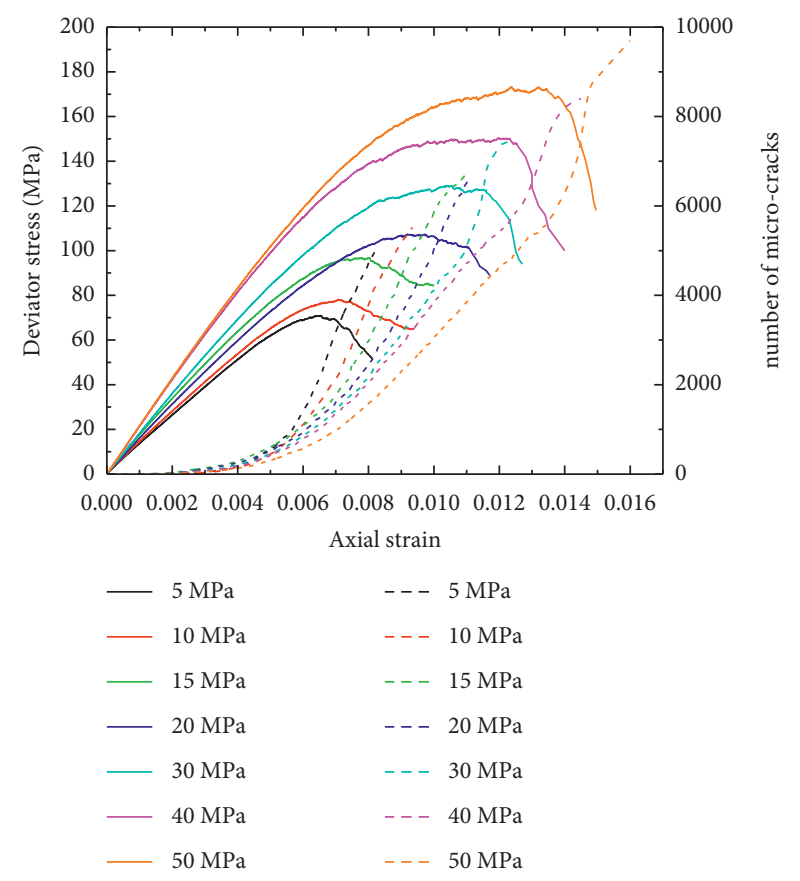

FIGURE 13: Deviator stress and microcracks number versus axial strain under different confining pressures (saturated).

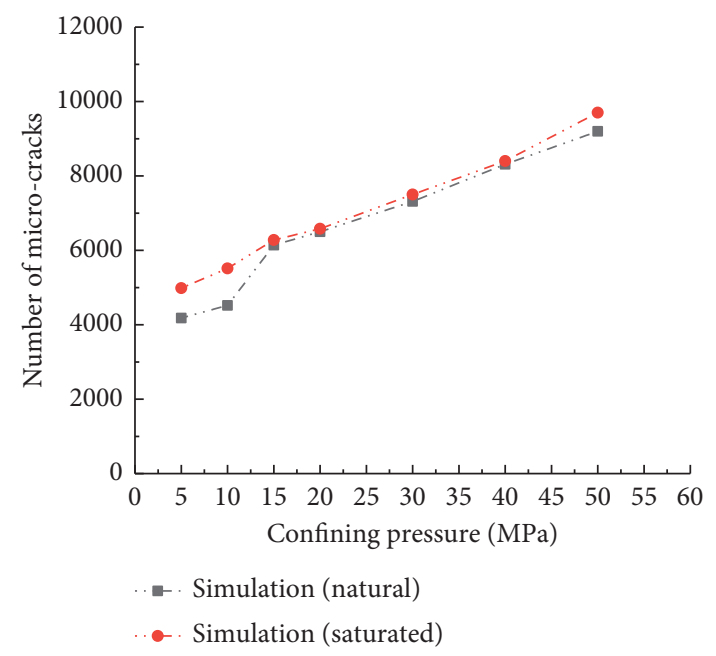

FIgURE 14: The diagram of microcracks under different confining pressures.

saturated sample increased slightly at a confining pressure of over $50 \mathrm{MPa}$. Accordingly, the difference in the fracture numbers between natural and saturated samples was widened with a further increase of the confining pressure. Future research studies will focus on this aspect.

Figure 15 shows the stress/strain curves and the fracture evolution rules of the samples with different moisture conditions at other confining pressures under the stress loading path. It is observed that the microfractures in the samples with varying states of moisture showed similar evolutional laws at different confining pressures (5 $\mathrm{MPa}$ and $15 \mathrm{MPa})$. The fracture initiation zones and rapid increase of microfractures in different samples exhibited no noticeable difference. It also 


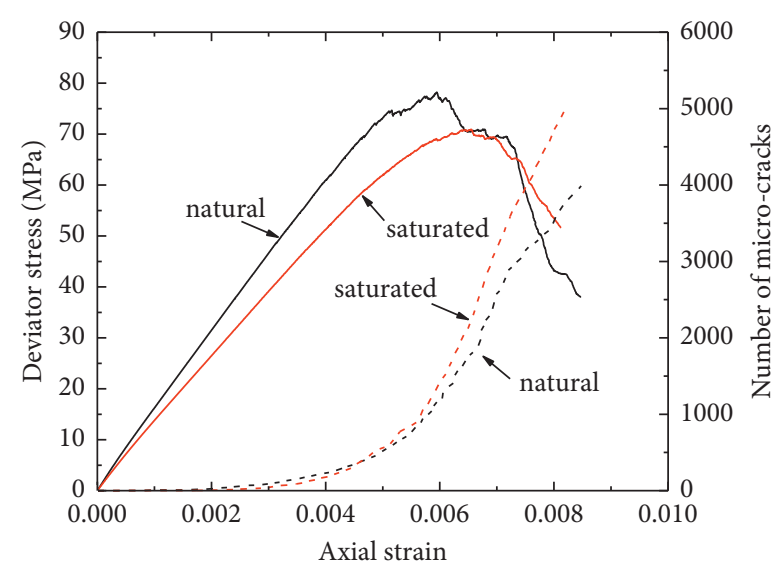

(a)

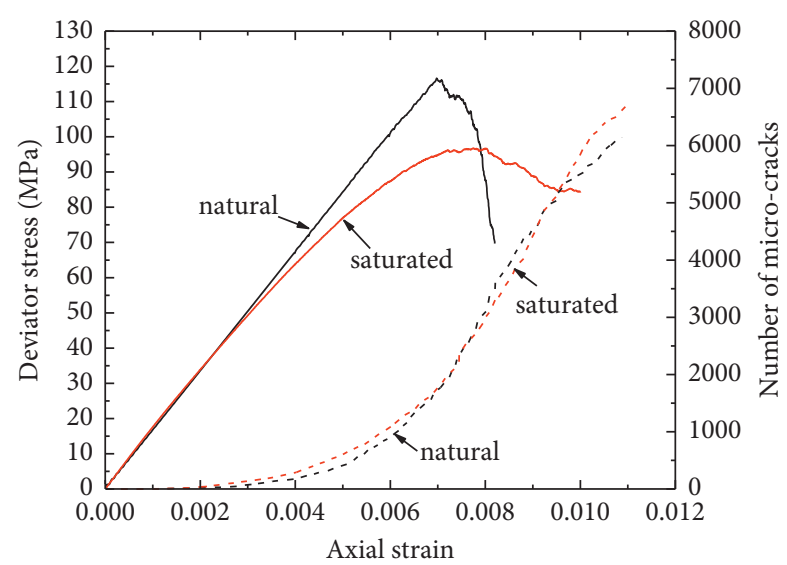

(b)

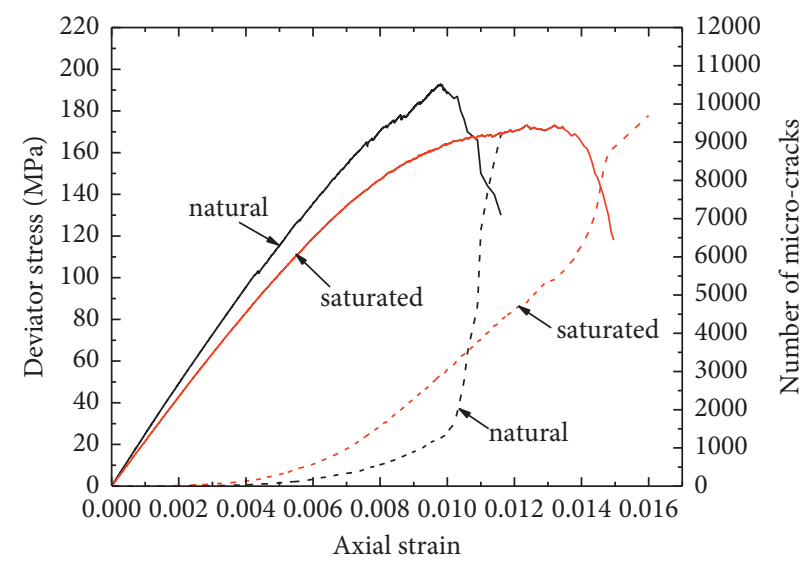

(c)

Figure 15: Deviator stress and microcracks number versus axial strain under different confining pressures. (a) $5 \mathrm{MPa}$, (b) $15 \mathrm{MPa}$, and (c) $50 \mathrm{MPa}$.

is observed that the number of the microfractures in the saturated sample was $20 \%$ higher than that in the natural sample at a confining pressure of $5 \mathrm{MPa}$, which is almost consistent with the scatter plots in Figure 14. At a high confining pressure, the evolution rules of the microfractures showed no noticeable difference. The number of microfractures in the natural sample increased very much when approaching the peak strength until failure. Because of the role of water, the saturated sample showed no apparent brittle failure while the peak stress increased significantly. At the beginning of loading, the microfractures in the saturated sample evolved more rapidly than those in the natural sample; subsequently, the microfractures increased stably. However, the increase of the microfractures in the saturated sample was slower than that in the natural sample, while the number of microfractures differs slightly in the two samples.

5.4. Force Chain Condition. Under axial load and gravity, the adjacent particles resulted in different strengths after the contact, which formed the force chains with uneven thickness distribution on a microscopic level. These force chains are interlaced in an irregular pattern to create the network. The strong force chains bore most external load while the weak force chains participated in the structural reconstruction in the material after the damages of particles and structural failure. The complexity of force chains on the micro level can account for totally different mechanical properties on the macro level. Without external load, the particles were in tight contact, and force chains were complexly interlaced. As shown in Figure 16, many longitudinal and transverse force chains were distributed throughout the sample.

After the application of external load, the distribution of force chains in the sample changed significantly. The force chains in the sample after loading failure were simulated by PFC software, during which the confining was set as $0,5,10$, $15,20,30,40$, and $50 \mathrm{MPa}$ (the present laboratory tests were performed at $0,5,10$, and $15 \mathrm{MPa})$. To be specific, the pressure force chains, marked in blue, occupied a vast majority after the damage, while the tensile force chains, marked in green, were unevenly distributed in the sample. The thickness of the force chain characterizes the magnitude of particle contact force. Thus, a thicker chain is indicative of greater particle contact force.

The force chain distribution underwent a significant change after failure. Before the loading, the force chains were intricately distributed. The number of longitudinal force 


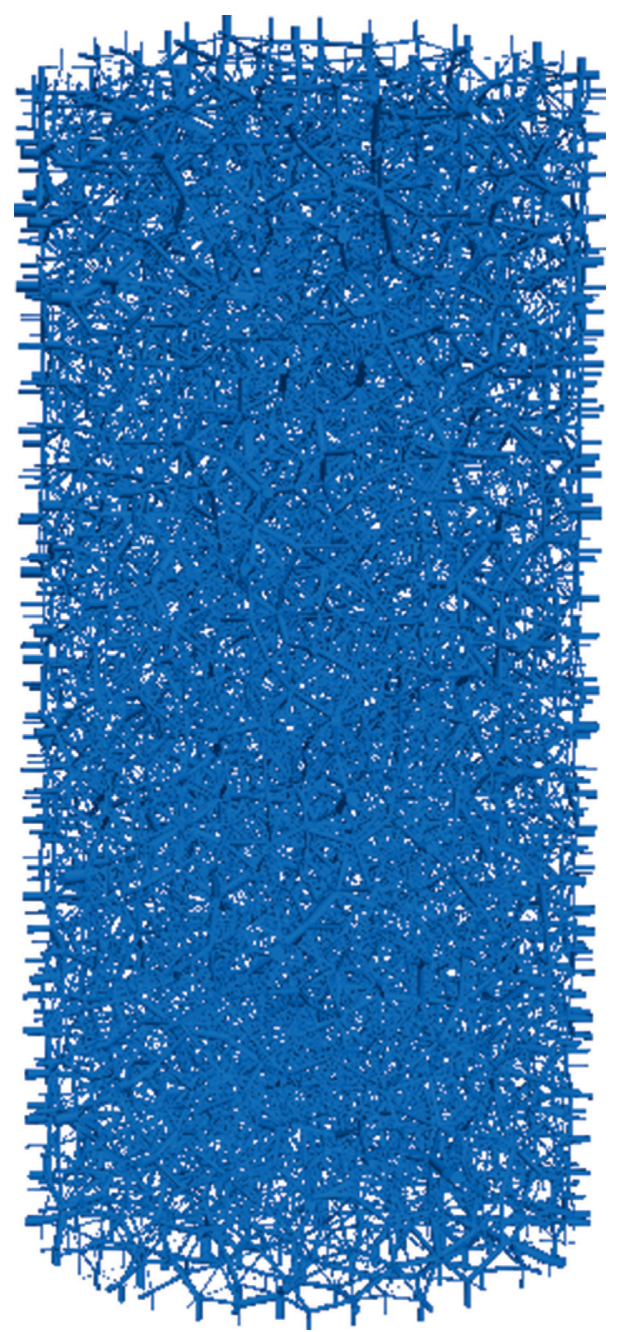

FIGURE 16: Initial force chain of the numerical model.

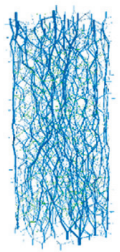

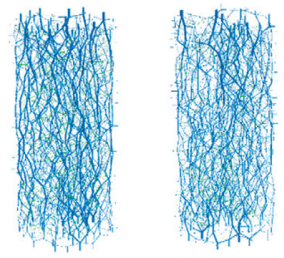

(a)
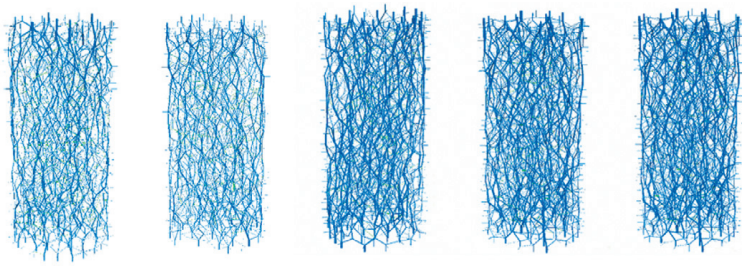

(b)

Figure 17: Force chain of natural samples after cracking. (a) Confining pressures are 0, 5, 10, and $15 \mathrm{MPa}$. (b) Confining pressures are 20, 30, 40 , and $50 \mathrm{MPa}$.

chains was more effective than that of transverse force chains. After the loading, the particles compressed as the load increased, accompanied by the increase of radial strain. The radial contact among particles was destroyed. A large number of radial force chains were fractured. Moreover, after the loading, many strong force chains, marked by thick lines in blue, can be found throughout the sample, whose directions were roughly identical with the loading direction. Only server strong force chains appeared at low confining pressure. As the confining pressure increased, strong force chains became more uniformly and densely distributed throughout the sample. The distributions of force chains in natural and saturated samples showed no noticeable difference. Thus, the confining pressure imposed a significant effect on the distribution of the force chain. After the failure, only several tensile force chains, marked in green, were faintly visible in 

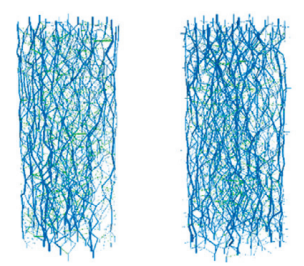

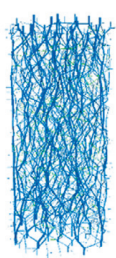

(a)

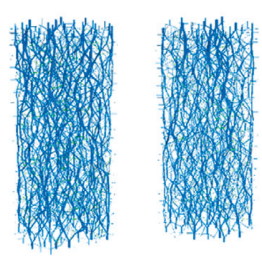

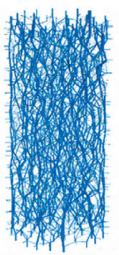

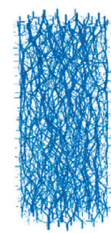

(b)

Figure 18: Force chain of the saturated sample after cracking. (a) Confining pressures are $0,5,10$, and $15 \mathrm{MPa}$. (b) Confining pressures are $20,30,40$, and $50 \mathrm{MPa}$.

the sample. Since most radial contacts were destroyed, only a few tensile force chains existed and were not obvious. By comparing the number of tensile force chains under different confining pressures, significantly fewer tensile force chains existed at higher confining pressure, and strong force chains showed the migration trend towards the confining pressure, as shown in Figures 17 and 18.

\section{Conclusions}

In this study, the microscopic numerical model of sandstone was established by PFC3D for numerical simulation. Through comparison, the microscopic numerical simulation results fit well with conventional uniaxial and triaxial test data in the laboratory.

The fracture initiation strengths of natural and saturated sandstone samples were $26 \%$ or $27 \%$ of peak strength. The microfractures developed slowly and then rapidly in exponential patterns after over $70 \% \sim 80 \%$ of peak strength in the early stage. The evolution of microfractures approximately followed an S-shaped pattern with the confining pressure, especially at high confining pressures. During the loading process, the number of shear fractures increased and gradually exceeded that of tensile fractures, finally leading to shear failure of the sample, consistent with macrofailure characteristics. At a confining pressure, the number of fractures in the saturated sample increased by $20 \%$. At high pressure, the number of fractures in the natural sample was close to that in the saturated sample.

After the loading, a significant number of strong force chains were distributed throughout the sample. Only several strong force chains were faintly visible at low confining pressure. As the confining pressure increased, the distribution of strong force chains became more uniform and denser. The natural and saturated samples showed almost no change in terms of force chain distribution. The confining pressure imposed a significant effect on the distribution of force chains.

This study revealed the deformation and failure rules of sandstone and microfracture development mechanism from a microscopic perspective, which can provide the micromechanical foundation for investigating the slope deformation and failure on the bank of the Three Gorge Reservoir. Furthermore, exploring microfracture evolution rules and deformation/failure mechanism of sandstone lays a solid foundation for evaluating the rock stability and predicting the occurrence of geological disasters in the reservoir.

\section{Data Availability}

The data used to support the findings of this study are available from the corresponding author upon request.

\section{Conflicts of Interest}

The authors declare that there are no conflicts of interest.

\section{Acknowledgments}

This research was funded by the Key Laboratory of Geological Hazards Mitigation for Mountainous Highway and Waterway, Chongqing Municipal Education Commission, Chongqing Jiaotong University (kfxm2018-10), the Fundamental and Advanced Research Projects of Chongqing (cstc2015jcyjA30003), and the Scientific and Technological Research Program of Chongqing Municipal Education Commission (kj1601336).

\section{References}

[1] Q. Wang, Z. Jiang, B. Jiang, H. Gao, Y. Huang, and P. Zhang, "Research on an automatic roadway formation method in deep mining areas by roof cutting with high-strength boltgrouting," International Journal of Rock Mechanics and Mining Sciences, vol. 128, p. 104264, 2020.

[2] C. Zhu, M. He, M. Karakus, X. Zhang, and Z. Guo, "The collision experiment between rolling stones of different shapes and protective cushion in open-pit mines," Journal of Mountain Science, vol. 18, no. 5, pp. 1391-1403, 2021.

[3] Q. Wang, Y. Wang, M. He, B. Jiang, S. Li, Z. Jiang et al., "Experimental research and application of automatically formed roadway without advance tunneling," Tunnelling and Underground Space Technology, vol. 114, no. 3, p. 103999, 2021.

[4] Q. Yin, J. Wu, C. Zhu, M. He, Q. Meng, and H. Jing, "Shear mechanical responses of sandstone exposed to high temperature under constant normal stiffness boundary conditions," Geomechanics and Geophysics for Geo-Energy and GeoResources, vol. 7, no. 2, pp. 1-17, 2021.

[5] Y. Wang, W. Feng, R. Hu, and C. Li, "Fracture evolution and energy characteristics during marble failure under triaxial fatigue cyclic and confining pressure unloading (FC-CPU) conditions," Rock Mechanics and Rock Engineering, vol. 54, no. 2, pp. 799-818, 2021.

[6] E. Hoek, Rock Engineering, A. A. Balkema Publishers, Rotterdam, Netherlands, 2005.

[7] J. F. Hazzard, R. P. Young, and S. C. Maxwell, "Micromechanical modeling of cracking and failure in brittle rocks," 
Journal of Geophysical Research: Solid Earth, vol. 105, no. B7, pp. 16683-16697, 2000.

[8] C. D. Martin and N. A. Chandler, "The progressive fracture of lac du bonnet granite," International Journal of Rock Mechanics and Mining Science \& Geomechanics Abstracts, vol. 31, no. 6, pp. 643-659, 1994.

[9] C. D. Martin, "Seventeenth Canadian geotechnical colloquium: the effect of cohesion loss and stress path on brittle rock strength," Canadian Geotechnical Journal, vol. 34, no. 5, pp. 698-725, 1997.

[10] E. Hoek and C. D. Martin, "Fracture initiation and propagation in intact rock-a review," Journal of Rock Mechanics and Geotechnical Engineering, vol. 6, no. 4, pp. 287-300, 2014.

[11] X. Zhang, S. Wang, G. Han, and B. Zhang, "Crack propagation study of rock based on uniaxial compressive test-a case study of schistose rock," Chinese Journal of Rock Mechanics and Engineering, vol. 30, no. 9, pp. 1772-1781, 2011.

[12] H. Xie, Y. Ju, L. Li, and R. Peng, "Energy mechanism of deformation and failure of rock masses," Chinese Journal of Rock Mechanics and Engineering, vol. 27, no. 9, pp. 1729-1740, 2008.

[13] Q. Meng, W. Xu, H. Wang, X. Zhuang, W. Xie, and T. Rabczuk, "DigiSim-an open source software package for heterogeneous material modeling based on digital image processing," Advances in Engineering Software, vol. 148, p. 102836, 2020.

[14] B. Li, R. Bao, Y. Wang, R. Liu, and C. Zhao, "Permeability evolution of two-dimensional fracture networks during shear under constant normal stiffness boundary conditions," Rock Mechanics and Rock Engineering, vol. 54, no. 3, pp. 1-20, 2021.

[15] H. Deng, J. Fang, J. Li, Y. Xiao, and M. Zhou, "Mechanical properties of red-bed soft rock on saturated state," Journal of China Coal Society, vol. 42, no. 8, pp. 1994-2002, 2017.

[16] Itasca Consulting Group, PFC3D (Particle Flow Code in 3 Dimensions) FISH in PFC3D, Itasca Consulting Group Inc., Minneapolis, MN, USA, 2008.

[17] P. A. Cundall and O. D. L. Strack, "A discrete numerical model for granular assemblies," Géotechnique, vol. 29, no. 1, pp. 47-65, 2008.

[18] N. Cho, C. D. Martin, and D. C. Sego, "A clumped particle model for rock," International Journal of Rock Mechanics and Mining Sciences, vol. 44, no. 7, pp. 997-1010, 2007.

[19] D. O. Potyondy and P. A. Cundall, "A bonded-particle model for rock," International Journal of Rock Mechanics and Mining Sciences, vol. 41, no. 8, pp. 1329-1364, 2004.

[20] A. Bäckström, J. Antikainen, T. Backers et al., "Numerical modelling of uniaxial compressive failure of granite with and without saline porewater," International Journal of Rock Mechanics and Mining Sciences, vol. 45, no. 7, pp. 1126-1142, 2008.

[21] A. Fakhimi, F. Carvalho, T. Ishida, and J. F. Labuz, "Simulation of failure around a circular opening in rock," International Journal of Rock Mechanics and Mining Sciences, vol. 39, no. 4, pp. 507-515, 2002.

[22] M. Jiang, P. Zhang, and Z. Liao, "Dem numerical simulation of rock under the influence of water softening and chemical weathering and chemical weathering in uniaxial compression test," Journal of China Institute of Water Resources and Hydropower Research, vol. 15, no. 2, pp. 89-95, 2017, in Chinese.

[23] X. Liu, L. Liang, L. Zhang, and Z. Wang, "Influence of wettingdrying cycles on mechanical properties and microstructure of shaly sandstone," Chinese Journal of Geotechnical Engineering, vol. 38, no. 7, pp. 1291-1300, 2016, in Chinese.
[24] C. Yu, Z. Wang, Y. Zheng, and X. Feng, "Experimental study on microscopic parameters of brittle materials based on particle flow theory," Chinese Journal of Geotechnical Engineering, vol. 37, no. 6, pp. 1031-1040, 2015, in Chinese.

[25] W. Tian, S. Yang, and Y. Huang, "Particle flow analysis of mechanical behavior and meso-mechanism sandstone under loading confining pressure," Rock and Soil Mechanics, vol. 37, no. Supp.2, pp. 775-782, 2016, in Chinese.

[26] K. Yuan, Y. Jiang, Y. Li, and G. Wang, "Macro-micro mechanical research on failure mechanism of rock subjected to compression loading based on DEM," Journal of Central South University, vol. 47, no. 3, pp. 913-922, 2016, in Chinese.

[27] D. Huang and X. Li, "Numerical simulation research on characteristic strength of marble based on development of microcrack," Rock and Soil Mechanics, vol. 38, no. 1, pp. 253-262, 2017, in Chinese. 